\title{
Age- and puberty-dependent association between IQ score in early childhood and depressive symptoms in adolescence
}

\author{
B. Glaser ${ }^{1,2 *}$, D. Gunnel1 ${ }^{2}$, N. J. Timpson ${ }^{1,2}$, C. Joinson ${ }^{3}$, S. Zammit ${ }^{3,4}$, G. Davey Smith ${ }^{1,2}$ and G. Lewis $^{3}$ \\ ${ }^{1}$ The MRC Centre for Causal Analyses in Translational Epidemiology, University of Bristol, Oakfield House, Oakfield Grove, Bristol, UK \\ ${ }^{2}$ Department of Social Medicine, University of Bristol, Canynge Hall, Bristol, UK \\ ${ }^{3}$ Department of Community Based Medicine, Cotham House, University of Bristol, Bristol, UK \\ ${ }^{4}$ Department of Psychological Medicine, School of Medicine, Cardiff University, Heath Park, Cardiff, UK
}

Background. Lower cognitive functioning in early childhood has been proposed as a risk factor for depression in later life but its association with depressive symptoms during adolescence has rarely been investigated. Our study examines the relationship between total intelligence quotient (IQ) score at age 8 years, and depressive symptoms at $11,13,14$ and 17 years.

Method. Study participants were 5250 children and adolescents from the Avon Longitudinal Study of Parents and their Children (ALSPAC), UK, for whom longitudinal data on depressive symptoms were available. IQ was assessed with the Wechsler Intelligence Scale for Children III, and self-reported depressive symptoms were measured with the Short Mood and Feelings Questionnaire (SMFQ).

Results. Multi-level analysis on continuous SMFQ scores showed that IQ at age 8 years was inversely associated with depressive symptoms at age 11 years, but the association changed direction by age 13 and 14 years (age-IQ interaction, $p<0.0001$; age squared-IQ interaction, $p<0.0001$ ) when a higher IQ score was associated with a higher risk of depressive symptoms. This change in IQ effect was also found in relation to pubertal stage (pubertal stage-IQ interaction, $0.00049<p \leqslant 0.038$ ). At age 17 years, however, sex-specific differences emerged (sex-age squared-IQ interaction, $p=0.0075$ ). Whilst the risk effect of higher childhood IQ scores for depressive symptoms declined in females, and some analyses even supported an inverse association by age 17 years, it persisted in males.

Conclusions. Our results suggest that the association between cognitive ability in childhood and depressive symptoms in adolescence varies according to age and/or pubertal stage.

Received 4 May 2009; Revised 24 March 2010; Accepted 25 March 2010; First published online 12 May 2010

Key words: Adolescence, ALSPAC, childhood, cognitive functioning, depressive symptoms.

\section{Introduction}

A large number of population-based cohort studies suggests that poor cognitive performance in childhood and early adulthood precedes depression (van Os et al. 1997; Zammit et al. 2004; Hatch et al. 2007; Koenen et al. 2009) and adverse mental health outcomes (Gunnell et al. 2002, 2005; Batty et al. 2005; Mortensen et al. 2005; Woodberry et al. 2008). Cognition may act as an indicator of 'system integrity' of the nervous system (Whalley \& Deary, 2001) and cognitive reserve,

\footnotetext{
* Address for correspondence: B. Glaser, Ph.D., MRC CAiTE/ University of Bristol, Oakfield House, Oakfield Grove, Bristol BS8 2BN, UK.

(Email: b.glaser@bristol.ac.uk)
}

a construct relating to intelligence (Scarmeas \& Stern, 2003) and more recently brain structure and functionality (Barnett et al. 2006), has been suggested as a mechanism that may underlie the association between early cognitive ability and later mental health outcome.

Cognitive and depression-related central nervous processes might be linked through hypothalamopituitary-adrenal (HPA) axis functions (Sapolsky et al. 1986; Lupien et al. 2009) as early adversity, a risk factor for depression (Goodman \& Brand, 2009), may via a dysregulation of the HPA axis affect complex cognitive processing and depressive symptomatology (Sapolsky et al. 1986; Lupien et al. 2009). Indeed, brain regions that are related to cognitive processes, such as the hippocampal formation, the amygdala

The online version of this article is published within an Open Access environment subject to the conditions of the Creative Commons Attribution-NonCommercial-ShareAlike licence <http://creativecommons.org/licenses/by-nc-sa/2.5/>. The written permission of Cambridge University Press must be obtained for commercial re-use. 
and the prefrontal cortex, are highly sensitive to stress hormones and show structural and functional changes in response to stress and during long-term depressive illness (McEwen, 2005; Romeo \& McEwen, 2006).

Although the association of early cognitive ability with depression in adulthood has been studied in a number of cohorts, little is known about this relationship in adolescence. Evidence relies so far on findings from a national British birth cohort born in 1946 (van Os et al. 1997), where an inverse relationship between cognitive ability at 8,11 and 15 years and affective disturbance at 13 or 15 years was reported.

Puberty demarcates the transition from childhood into adulthood and is accompanied by rapid changes in biological, cognitive and social factors (Conger \& Galambos, 1996): HPA and hypathalamo-pituitarygonadal axis functions are reshaped during puberty (McCormick \& Mathews, 2007; Lupien et al. 2009), brain regions implicated in stress reactivity and emotionality mature during adolescence (Romeo \& McEwen, 2006) and there is increased ability for more abstract, multidimensional, planned and hypothetical thinking (Keating, 2004; Steinberg, 2005). Puberty, however, is also a period of increased vulnerability and adjustment (Caspi \& Moffitt, 1991), as adolescents may experience transitional stress due to new psychological adaptations and an accumulation of stressful events (e.g. Rudolph \& Hammen, 1999), but also stress related to disparities between their chronological age, social age and biological maturation (e.g. 'early maturation' hypothesis; Peterson \& Taylor, 1980).

Thus, it is plausible that pubertal maturation may affect the relationship between early cognitive processes and later depressive symptomatology. It is therefore important to take a developmental perspective when studying this time in life, especially as puberty has been associated with an increased risk of affective symptoms (Angold et al. 1998).

Our study seeks to investigate the association between childhood cognitive ability, as measured through intelligence quotient (IQ) scores, and depressive symptomatology in adolescence by studying members of the Avon Longitudinal Study of Parents and Children (ALSPAC).

The specific aims of the study were:

(1) To investigate the association of childhood IQ score at age 8 years with depressive symptoms at $11,13,14$ and 17 years.

(2) To study the relationship between IQ score and depressive symptoms according to pubertal maturation.

\section{Method}

Study samples: sample description

All pregnant women in the Bristol area (UK) with an expected delivery between April 1991 and December 1992 were approached for participation in the study, resulting in 14092 live births. A detailed description of the cohort has been published previously (Golding et al. 2001). Ethical approval was obtained from the ALSPAC Law and Ethics Committee and the Local Research Ethics Committees. Children included in this analysis were White European singletons with a total IQ of $\geqslant 70$ (see below), indicating cognitive abilities within the normal range or above. To minimize the impact of depressive symptoms at baseline on measured IQ score, children with a clinical diagnosis of depression or anxiety at age 8 years, using the Development and Well-Being Assessment (Goodman et al. 2000), were excluded. This resulted in 5250 eligible individuals (2589 boys, 2661 girls). Depressive symptoms in children were measured at ages 11 years (mean $=10.6$, S.D. $=0.20$, range 9.9-12.1 years), 13 years $($ mean $=12.8$, S.D. $=0.19$, range 11.8-14.1 years $), 14$ years $($ mean $=13.8$, s.D. $=0.18$, range $12.6-14.9$ years $)$ and 17 years $($ mean $=16.7$, S.D. $=0.24$, range $16.4-17.7$ years). Attrition rates for depressive symptoms varied between $11.20 \%$ (age 11 years), 18.23\% (age 13 years), $24.25 \%$ (age 14 years) and $40.19 \%$ (age 17 years). The attrition rate at age 17 years was higher, as at this age the measurement of depressive symptoms was carried out via mailed questionnaires, whereas during earlier assessments the questionnaire was filled in within a research clinic setting (see below). Complete information on baseline IQ, potential confounders and depressive symptoms at $11,13,14$ and 17 years was available for 2252 (42.89\%) eligible individuals.

\section{Measures \\ IQ measures}

IQ score at age 8 years was measured with the Wechsler Intelligence Scale for Children (WISC-III; Wechsler et al. 1992). A short version of the test consisting of alternate items only (except the coding task) was applied by trained psychologists (Adebamowo et al. 2007). Verbal (information, similarities, arithmetic, vocabulary, comprehension) and performance (picture completion, coding, picture arrangement, block design, object assembly) subscales were administered, the subtests scaled according to age, and scores for total IQ derived. Although there is considerable evidence that general intellectual abilities improve during the course of development (Keating, 2004), scaled IQ scores are designed to correct for this 
progression, so that the rank order of individuals is potentially maintained over time (Court \& Raven, 1982 ; Fry \& Hale, 2000).

\section{Depressive symptoms}

Self-reported depressive symptoms were measured with the 13-item Short Mood and Feelings Questionnaire (SMFQ; Angold et al. 1995), which has high reliability and validity (Angold et al. 1995). Statements are rated on a three-point scale $(0=$ 'not true', $1=$ 'sometimes true', $2=$ 'true'). Self-reported rather than parent-reported SMFQ scores were assessed, as parent-reported scores do not reveal depressive symptoms as early as self-reported measures (Cole et al. 2002). In view of concerns regarding the reading and understanding ability of younger children (Thapar \& McGuffin, 1998), the questionnaire was read out by a psychologist for children at age 11 years. The psychologist was passively recording answers and was only allowed to explain the questions to the participants. For adolescents aged 13 and 14 years, the questionnaire was administered in computerized form within a clinical setting, and any difficulties arising, such as those related to understanding of the questions, could be resolved by clinic staff. At age 17 years, the questionnaire was sent out by mail.

\section{Pubertal maturation}

Pubertal stage at 11, 13 and 14 years was measured using a five-point rating scale (Tanner, 1962). For males and females, it was assessed as the extent of pubic hair. For females, pubertal stage was also assessed as the extent of breast growth, as there is evidence that girls may experience asynchronous pubertal maturation with respect to breast bud and pubic hair development (Biro et al. 2003). The majority of pubertal assessments were taken within 1 year after the measurement of depressive symptoms (data not shown). As depression scores are likely to rise during adolescence, this may weaken but not bias an underlying association. However, any pubertal assessment that was taken more than 1 year before the measurement of depressive symptoms was excluded from the analysis. Pubertal measures at age 17 years are not available yet.

\section{Potential confounders}

The following information was collected from mothers and their partners at 18 and 32 weeks of pregnancy:

Occupational social class. Occupational social class was derived as the lower of either maternal or paternal social class and dichotomized into 'non-manual' (I, II,
III-non-manual) and 'manual' (III-manual, IV, V) work (Dale \& Marsh, 1993).

Maternal education. Information on maternal education was categorized into 'below O-level', 'O-level' and 'above O-level' (O-levels are school tests taken approximately at age 16 years in England).

Housing tenure. Housing tenure information was classified into 'mortgaged or owned', 'privately rented', 'council or housing authority' or 'other'.

Family history of psychiatric disorders. Parent-reported family history of psychiatric disorders (ALSPAC questionnaire) was coded as present, if either parents or grandparents suffered from mental disorders ['yes' (depression, schizophrenia, other), 'no'].

Single-parent family status. Single-parent family status was given for widowed, divorced or separated mothers ('yes', 'no').

Data were also collected during childhood:

General mental health. General mental health based on mother report at age 8 years was assessed using the continuous total behavioural difficulties summary score of the Strength and Difficulties Questionnaire (Goodman, 1997), which covers areas of emotional and behavioural difficulties. An adjustment for emotional and behavioural difficulties at baseline is important, in order to control for the potential influence on IQ test performance.

Psychosis-like symptoms (PLIKS)

PLIKS scores were investigated as part of a sensitivity analysis, as the previously reported association between IQ score at age 8 years and PLIKS at age 12 years (Horwood et al. 2008) raised the possibility that the association between childhood IQ and depressive symptoms in adolescence might be confounded by other pre-clinical symptoms. PLIKS scores in ALSPAC children were measured at the age of 12 years using a semi-structured interview (PLIKSi; Horwood et al. 2008). This consisted of 12 core questions covering the past 6-month occurrence of hallucinations, delusions and experiences of thought interference. Symptoms were rated as either not present, suspected or definitely present. Present symptoms were only included in the analysis if not attributable to sleep, fever or substance use.

\section{Statistical methods}

All analyses were carried out using R (CRAN, 2008). 


\section{Potential confounder analysis}

Sex- and age-adjusted means for measures of cognitive functioning were calculated from ordinary leastsquare regression of potential confounding variables (i.e. maternal education, parental social class, singleparent status, general mental health). Sex and age were adjusted for each other. For confounder analysis only, general mental health at age 8 years was dichotomized into problems present ('yes' $\geqslant 17$ ) or absent ('no' <17) (Goodman, 1997).

\section{Association analysis}

The continuous change in SMFQ scores over time was analysed as a function of Z-transformed baseline IQ, using both single-level Poisson regression models that model the data at each time point of the SMFQ assessment, and can be easily applied to multiply imputed data sets, and multi-level (mixed) Poisson regression models (lme4 library; Bates \& Maechler, 2009) that allow the modelling of parameters of change with respect to baseline IQ scores (Blance et al. 2005). A Poisson distribution has been selected in accordance with previous research (Angold et al. 2002). For all analyses, age was modelled continuously in years at SMFQ assessment.

For single-level analysis, baseline IQ estimates were corrected for sex and age at SMFQ assessment (crude models), in addition to maternal education, parental social class, housing tenure, single-parent family status, family history of psychiatric disorders and general mental health at baseline (adjusted models). Single-level Poisson models were also compared with single-level quasi-Poisson regression models that allow for an overdispersion of the data.

For multi-level analysis (crude models), the change in depressive symptoms over time was captured through age, age squared, age-sex, age-IQ, age squared-sex and age squared-IQ effects. These fixed effects were added sequentially and the improvement in model fit was confirmed using likelihood ratio tests (LRTs). Models were fitted with random intercepts and slopes for age and age squared (best model fit; data not shown). Models were additionally adjusted for potential confounders (adjusted models, as described above) and covariates were included as fixed effects. In addition, age-general mental health and age squared-general mental health fixed effects were added to allow for a change in baseline covariate effects. Within mixed Poisson models overdispersion was captured through the variance of the random error (Gelman \& Hill, 2007).

Statistical significance of model terms in single-level and multi-level analyses was assessed using Wald tests. The statistical significance of interactions was confirmed with LRTs. In the presence of sex-specific IQ effects (single-level model: sex-IQ interaction; multi-level model: sex-IQ, sex-age-IQ or sex-age squared-IQ interaction), the analysis was repeated for both sexes separately. Exponentiated Poisson regression estimates, $\exp (\beta)$, were reported as symptom count ratios (SCRs). These can be interpreted as a percentage change of the outcome for every increase in one predictor unit (Gelman \& Hill, 2007), given as $(\mathrm{SCR}-1) \times 100$. For example, SCR $=1.10$ would refer to a $10 \%$ increase in SMFQ scores per increase in 1 s.D. of IQ in our study.

The influence of pubertal maturation on the relationship between cognitive ability in childhood and depression in adolescence was studied with a similar multi-level model as described above, but replacing age at SMFQ assessment by Tanner stage. However, as a fixed effect of pubertal stage squared did not improve the model fit, this term and all associated interactions were excluded. All models were fitted with random intercepts and slopes for pubertal stage and pubertal stage squared (best model fit; data not shown). The analysis was carried out for each sex separately.

Sensitivity analyses were performed to assess the robustness of the reported findings to the presence of missing data. Specifically, we compared single-level Poisson regression estimates in original and imputed datasets, using crude and adjusted models (see above). Imputed data $(n=5250)$ were generated with an imputation-by-chained-equation approach (Oudshoorn et al. 1999), which allowed for sex differences (10 multiply imputed datasets; mice library). Imputations were also repeated for each sex separately.

As part of a further sensitivity analysis, we assessed whether PLIKS at age 12 years affected the relationship between childhood IQ and later depressive symptomatology (see above). For this, PLIKS was included as a fixed effect in an adjusted mixed Poisson model (see above).

\section{Results}

\section{Analysis of potential confounders}

Based on a sample of 2252 individuals with complete data, the median IQ at 8 years (mean age $=8.6$, S.D. $=0.19$ years) was 109 (s.D. $=14.96)$. Lower IQ scores at baseline were more frequent in children who were older (as later attendance of the research clinic was associated with lower socio-economic status; data not shown), who had more general mental health problems (measured as emotional and behavioural difficulties) at 8 years, who lived in single-parent families and whose parents had a lower socio-economic 
Table 1. Association between potential confounders and IQ at age 8 years, based on a sample with complete information (total $n=2252)$

\begin{tabular}{|c|c|c|c|c|}
\hline Potential confounder & $n$ & $\beta$ & S.E. & $p$ \\
\hline Age at IQ assessment ${ }^{\mathrm{a}}$ & & & & 0.005 \\
\hline 96-99 months & 206 & 110.42 & 1.04 & \\
\hline 100-103 months & 1512 & 110.06 & 1.11 & \\
\hline 104-107 months & 495 & 107.28 & 1.24 & \\
\hline 108-111 months & 19 & 107.17 & 3.58 & \\
\hline$\geqslant 112$ months & 20 & 106.49 & 3.49 & \\
\hline Sex ${ }^{b}$ & & & & 0.14 \\
\hline Female & 1265 & 109.01 & 0.42 & \\
\hline Male & 987 & 109.95 & 0.63 & \\
\hline Maternal education $^{c}$ & & & & $<0.0001$ \\
\hline Below O-level & 138 & 101.38 & 1.24 & \\
\hline O-level & 905 & 104.9 & 1.31 & \\
\hline Above O-level & 1209 & 113.07 & 1.28 & \\
\hline Parental social class ${ }^{c}$ & & & & $<0.0001$ \\
\hline Manual & 205 & 102.53 & 1.07 & \\
\hline Non-manual & 2047 & 109.69 & 1.08 & \\
\hline Housing tenure ${ }^{c}$ & & & & $<0.0001$ \\
\hline Council & 84 & 100.12 & 1.64 & \\
\hline Privately rented & 92 & 109.6 & 2.24 & \\
\hline Mortgaged or owned & 2027 & 109.41 & 1.65 & \\
\hline Other & 49 & 108.73 & 2.67 & \\
\hline Single-parent family ${ }^{c}$ & & & & 0.025 \\
\hline No & 1941 & 109.3 & 0.44 & \\
\hline Yes & 311 & 107.25 & 0.91 & \\
\hline $\begin{array}{l}\text { Family history of } \\
\text { mental disorders }\end{array}$ & & & & 0.31 \\
\hline No & 1270 & 108.74 & 0.5 & \\
\hline Yes & 982 & 109.39 & 0.64 & \\
\hline $\begin{array}{l}\text { General mental } \\
\text { health problems }\end{array}$ & & & & $<0.0001$ \\
\hline No & 2164 & 109.23 & 0.42 & \\
\hline Yes & 88 & 102.83 & 1.62 & \\
\hline
\end{tabular}

IQ, Intelligence quotient; S.E., standard error.

a Obtained at age 8 years.

${ }^{b}$ Obtained at birth.

${ }^{\mathrm{C}}$ Obtained during pregnancy.

position including a lower maternal education, manual parental social class and council housing. There was no difference in IQ between sexes (Table 1).

\section{Age-related distribution of SMFQ scores}

The inspection of SMFQ scores revealed a rightskewed distribution at all four measurement time points. The median of SMFQ scores was 3 (s.D. $=3.35$, range $0-20$ ) at 11 years, it remained at 3 (s.D. $=3.61$, range $0-24$ ) at 13 years but shifted towards 4 at 14 and 17 years (s.D. $=4.21$, range $0-24$ and S.D. $=5.36$, range 0-26, respectively).

\section{Age-related association between baseline IQ and SMFQ scores}

Single-level analysis found an inverse relationship between IQ scores at age 8 years and SMFQ scores at age 11 years within the complete sample of ALSPAC children (see Table 2). Specifically, the increase in 1 S.D. of baseline IQ was associated with a 7\% decrease in SMFQ scores $[\mathrm{SCR}=0.93,95 \%$ confidence interval $(\mathrm{CI})$ 0.92-0.95, adjusted model]. This association changed direction at ages 13 and 14 years (see Table 2) such that an increase in 1 S.D. of baseline IQ was associated with a $4 \%(\mathrm{SCR}=1.04,95 \% \mathrm{CI} 1.02-1.06)$ and $3 \%$ increase $(\mathrm{SCR}=1.03,95 \%$ CI 1.02-1.05) in SMFQ scores, respectively (adjusted model). At age 17 years, however, strong sex differences in the IQ effect were observed (sex-IQ interaction, $Z=5.44, p<0.0001$, adjusted model, see Table 2). Sex-specific analysis revealed a further change in the direction of the IQ effect in females. This manifested as a $2 \%(S C R=0.98$, 95\% CI 0.96-1.00, adjusted model) decrease in SMFQ scores per 1 S.D. in IQ. For males, the risk effect of baseline IQ, as observed during early adolescence, however, persisted at age 17 years as a $9 \%(S C R=1.09$, 95\% CI 1.06-1.13, adjusted model) increase in SMFQ scores per 1 s.D. in IQ. Similar associations were also found using imputed data (see Table 2), and QuasiPoisson regression models (see also Supplementary Table S1, available online). None of the observed associations with IQ score was substantially altered by adjustment (see Table 2).

In extending the single-level models at 11, 13, 14 and 17 years, parameters of change for the relationship between IQ score at age 8 years and depressive symptoms in later life were estimated with multilevel analyses that derive trajectories of depressive symptoms over time (see Fig. 1). Multi-level model estimates were similar to those from single-level analyses (adjusted models only are presented, see Supplementary Table S1). The age-dependency of the association between IQ score at age 8 years and depressive symptoms during adolescence was reflected by an age-IQ interaction $(Z=5.73, p<0.0001)$ and an age squared-IQ interaction $(Z=-4.10, p<0.0001)$ within the complete sample of ALSPAC children $(n=2252)$. The evidence for a non-linear change in the IQ effect across the modelled age range was particularly true in females (sex-age squared-IQ interaction, $Z=2.67, p=0.0075$, see Fig. $1 b$ ). As expected, there was support for age-sex $(Z=-11.77, p<0.0001)$ and age squared-sex effects $(Z=2.26, p=0.023)$ within the complete sample: Compared with females, males had fewer depressive symptoms during mid and late adolescence (age 13 years, SCR $=0.77,95 \%$ CI 0.72 0.83 ; age 14 years, $\mathrm{SCR}=0.70,95 \%$ CI $0.65-0.75$; age 
Table 2. Association between baseline total $I^{a}$ score and depressive symptoms (SMFQ scores): single-level analysis

\begin{tabular}{|c|c|c|c|c|c|c|c|c|c|}
\hline \multirow[b]{2}{*}{ Sample } & \multirow[b]{2}{*}{$\mathrm{Age}^{\mathrm{c}}$} & \multicolumn{4}{|c|}{ Original data } & \multicolumn{4}{|c|}{ Imputed data ${ }^{b}$} \\
\hline & & $n$ & $\begin{array}{l}\mathrm{SCR}^{\mathrm{d}} \\
(95 \% \mathrm{CI})\end{array}$ & $\begin{array}{l}\text { Adjusted SCR } \\
(95 \% \mathrm{CI})\end{array}$ & $p$ Sex-IQ ${ }^{\mathrm{f}}$ & $n$ & $\begin{array}{l}\mathrm{SCR}^{\mathrm{d}} \\
(95 \% \mathrm{CI})\end{array}$ & $\begin{array}{l}\text { Adjusted SCR } \\
(95 \% \mathrm{CI})\end{array}$ & $p$ Sex-IQ ${ }^{f}$ \\
\hline \multirow[t]{4}{*}{ All } & 11 & 3961 & $0.91(0.89-0.92)$ & $0.93(0.92-0.95)$ & $0.057^{\mathrm{d}}, 0.076^{\mathrm{e}}$ & 5250 & $0.91(0.89-0.92)$ & $0.93(0.92-0.95)$ & $0.048^{\mathrm{d}}, 0.040^{\mathrm{e}}$ \\
\hline & 13 & 3675 & $1.02(1.01-1.04)$ & $1.04(1.02-1.06)$ & $0.70^{\mathrm{d}}, 0.62^{\mathrm{e}}$ & 5250 & $1.01(0.99-1.02)$ & $1.02(1.00-1.04)$ & $0.48^{\mathrm{d}}, 0.50^{\mathrm{e}}$ \\
\hline & 14 & 3417 & $1.02(1.00-1.03)$ & $1.03(1.02-1.05)$ & $0.070^{\mathrm{d}}, 0.039^{\mathrm{e}}$ & 5250 & $1.01(0.99-1.03)$ & $1.03(1.01-1.05)$ & $0.065^{\mathrm{d}}, 0.068^{\mathrm{e}}$ \\
\hline & 17 & 2754 & $0.99(0.98-1.01)$ & $1.02(1.00-1.04)$ & $<0.0001^{\mathrm{d}, \mathrm{e}}$ & 5250 & $0.99(0.97-1.01)$ & $1.01(0.99-1.03)$ & $0.0043^{\mathrm{d}}, 0.0044^{\mathrm{e}}$ \\
\hline \multirow[t]{4}{*}{ Males } & 11 & 1929 & $0.92(0.90-0.94)$ & $0.95(0.92-0.97)$ & - & 2589 & $0.92(0.90-0.94)$ & $0.94(0.92-0.97)$ & - \\
\hline & 13 & 1776 & $1.02(1.00-1.05)$ & $1.03(1.01-1.06)$ & - & 2589 & $1.00(0.97-1.03)$ & $1.02(0.99-1.05)$ & - \\
\hline & 14 & 1657 & $1.00(0.98-1.02)$ & $1.02(0.99-1.04)$ & - & 2589 & $0.99(0.97-1.02)$ & $1.01(0.98-1.04)$ & - \\
\hline & 17 & 1181 & $1.06(1.03-1.09)$ & $1.09(1.06-1.13)$ & - & 2589 & $1.04(0.99-1.10)$ & $1.08(1.02-1.13)$ & - \\
\hline \multirow[t]{4}{*}{ Females } & 11 & 2032 & $0.89(0.87-0.91)$ & $0.92(0.89-0.94)$ & - & 2661 & $0.89(0.87-0.91)$ & $0.91(0.89-0.93)$ & - \\
\hline & 13 & 1899 & $1.03(1.01-1.05)$ & $1.04(1.02-1.07)$ & - & 2661 & $1.02(1.00-1.04)$ & $1.03(1.01-1.06)$ & - \\
\hline & 14 & 1760 & $1.03(1.01-1.05)$ & $1.05(1.03-1.08)$ & - & 2661 & $1.03(1.01-1.05)$ & $1.05(1.03-1.08)$ & - \\
\hline & 17 & 1573 & $0.96(0.94-0.98)$ & $0.98(0.96-1.00)$ & - & 2661 & $0.96(0.94-0.98)$ & $0.98(0.96-1.00)$ & - \\
\hline
\end{tabular}

IQ, Intelligence quotient; SMFQ, Short Mood and Feelings Questionnaire; SCR, symptom count ratio exp $(\beta) ; C I$, confidence interval.

${ }^{a}$ Measured in standard deviations.

${ }^{\mathrm{b}}$ Imputed data analysis based on 10 imputed datasets.

${ }^{c}$ Rounded mean age in years.

$\mathrm{d}$ Adjusted for sex and age at SMFQ ascertainment.

e Adjusted for sex, age at SMFQ ascertainment, maternal education, parental social class, housing tenure, single parent family status, family history of psychiatric disorders and general mental health at age 8 years.

${ }^{\mathrm{f}} \mathrm{Sex}-\mathrm{IQ}$ interaction effects. 
(a)

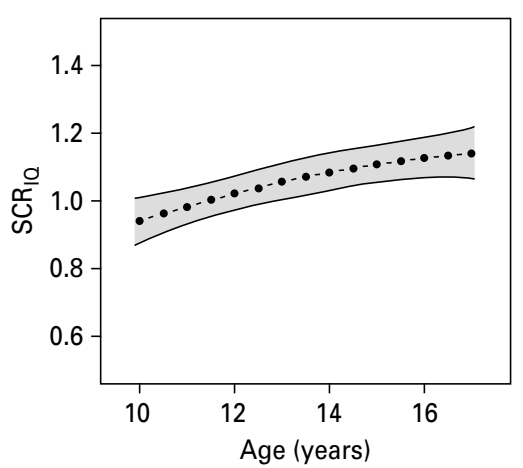

(b)

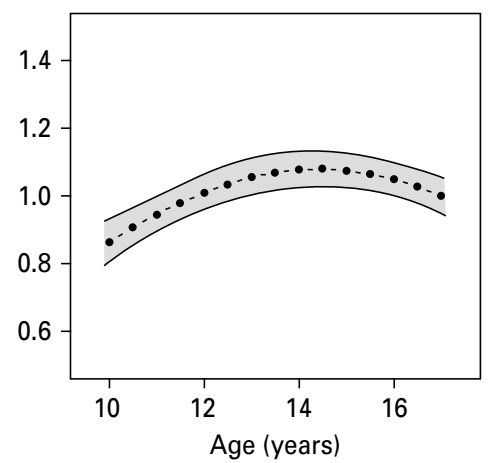

Fig. 1. Association between total intelligence quotient (IQ) score at age 8 years and depressive symptoms (Short Mood and Feelings Questionnaire scores) during adolescence in males $(a)$ and females $(b)$. Estimates were derived for males $(n=987)$ and females ( $n=1265)$ using adjusted sex-specific multi-level Poisson models. The IQ effect is depicted as symptom count ratio (SCR) as given by $\exp (\beta)(-\bullet-\bullet-)$, with $95 \%$ confidence intervals $(-)$.

17 years, SCR $=0.58,95 \%$ CI $0.54-0.62$ ), although they showed similar rates to females at age 11 years $(\mathrm{SCR}=1.02,95 \%$ CI 0.94-1.10).

There was no substantial alteration in multi-level model estimates after adjustment (data not shown). Quasi-Poisson multi-level models provided similar results (data not shown).

Sensitivity analysis was performed to assess whether the observed association with IQ score was confounded by PLIKS. There was no evidence for an attenuation of the observed baseline IQ effect in PLIKS-adjusted mixed models. For example, conditional IQ estimates from PLIKS-adjusted models, reported for the mean age at SMFQ assessment (age 11 years, $\mathrm{SCR}=0.94,95 \% \mathrm{CI} 0.90-0.98$; age 13 years, $\mathrm{SCR}=1.05,95 \%$ CI 1.01-1.09; age 14 years, $\mathrm{SCR}=1.08$, $95 \%$ CI 1.04-1.12; age 17 years, $\mathrm{SCR}=1.07,95 \%$ CI 1.03-1.11), were similar to those from PLIKSunadjusted models (see Supplementary Table S1).

\section{Pubertal stage-related association between baseline $I Q$ and SMFQ scores}

As part of a secondary analysis, we also studied whether the relationship between baseline IQ and depressive symptoms during adolescence was related to pubertal maturation. For this, we used the multi-level model approach but substituted age by pubertal maturation as given by Tanner score (see Table 3 ). Tanner scores were only available at 11, 13 and 14 years, and complete data were restricted to a small subsample in ALSPAC (boys: $n=718$, pubic hair; girls: $n=948$, pubic hair; girls: $n=955$, breast growth).

Consistent with the findings for age, this study found that the association of IQ scores with later depressive symptoms differed according to pubertal stage, manifesting as pubertal stage-IQ interaction in boys (pubic hair, $Z=2.07, p=0.038$ ) and girls (pubic hair, $Z=3.30, p=0.00098$; breast growth, $Z=3.49$, $p=0.00049$; adjusted model). For both males and females, the association changed direction between Tanner stages 1 and 5, although the effects were weaker in males (see Table 3). Data on pubertal maturation at age 17 years that may reveal further changes in the IQ effect are not available yet.

\section{Discussion}

This population-based study provided evidence for a complex relationship between IQ scores at age 8 years and depressive symptoms during adolescence. For both males and females, total IQ score at age 8 years was inversely related to depressive symptoms at age 11 years. The effect, however, changed over time such that higher baseline IQ was associated with higher depressive symptoms at ages 13 and 14 years. These findings were consistent with the analysis in relation to pubertal stage. At age 17 years, however, strong sex-specific differences emerged. In females, this manifested as a decline in risk effects of higher baseline IQ with a potential reversal of the effect by age 17 years. In males, the risk effect of higher baseline IQ for later depressive symptoms, however, persisted (see Fig. 1a).

Compared with previous research, our findings in female adolescents at age 17 years are in line with studies that observed an inverse relationship between childhood cognitive ability and self-reported continuous subclinical measures of depression in women (Hatch et al. 2007). The observed association between higher childhood IQ scores and depressive symptoms at 13 and 14 years (and in males at 17 years) 
Table 3. Association between baseline total I $Q^{\mathrm{a}}$ score and depressive symptoms (SMFQ scores) by pubertal development (Tanner stage) at ages 11, 13 and 14 years $^{\mathrm{b}}$

\begin{tabular}{lcl}
\hline & \multicolumn{1}{l}{$\begin{array}{l}\mathrm{SCR}^{\mathrm{d}} \\
(95 \% \mathrm{CI})\end{array}$} & $\begin{array}{l}\text { Adjusted SCR } \\
(95 \% \mathrm{CI})\end{array}$ \\
\hline $\begin{array}{l}\text { Tanner stage }^{\mathrm{c}} \\
\text { Boys }(n=718)\end{array}$ & $\begin{array}{l}\text { Pubic hair } \\
1\end{array}$ & $0.93(0.87-1.00)$ \\
2 & $0.92(0.86-0.99)$ & $0.96(0.91-1.01)$ \\
3 & $0.97(0.90-1.00)$ & $0.98(0.93-1.04)$ \\
4 & $1.00(0.94-1.06)$ & $1.01(0.95-1.08)$ \\
5 & $1.02(0.95-1.11)$ & $1.04(0.96-1.12)$ \\
Girls $(n=948)$ Pubic hair & \\
1 & $0.89(0.84-0.96)$ & $0.91(0.85-0.97)$ \\
2 & $0.93(0.88-0.98)$ & $0.94(0.89-1.00)$ \\
3 & $0.97(0.92-1.02)$ & $0.98(0.93-1.03)$ \\
4 & $1.01(0.96-1.07)$ & $1.02(0.96-1.07)$ \\
5 & $1.05(0.99-1.13)$ & $1.06(0.99-1.13)$ \\
Girls $(n=955)$ Breast development & \\
1 & $0.88(0.82-0.94)$ & $0.89(0.82-0.95)$ \\
2 & $0.92(0.87-0.98)$ & $0.93(0.88-0.99)$ \\
3 & $0.97(0.93-1.02)$ & $0.98(0.93-1.03)$ \\
4 & $1.02(0.97-1.08)$ & $1.03(0.97-1.09)$ \\
5 & $1.08(1.00-1.16)$ & $1.08(1.00-1.16)$ \\
\hline
\end{tabular}

IQ, Intelligence quotient; SMFQ, Short Mood and Feelings Questionnaire; SCR, symptom count ratio $\exp (\beta)$; $\mathrm{CI}$, confidence interval.

${ }^{a}$ Measured in standard deviations.

${ }^{\mathrm{b}}$ Pubertal measures corresponding at age 17 years are not available yet.

${ }^{c}$ Conditional estimates are reported for Tanner stages 1 to 5 , respectively, based on the estimated pubertal stage and pubertal stage-IQ interaction effect in multi-level analysis.

${ }^{\mathrm{d}}$ Crude association.

e Adjusted for maternal education, parental social class, housing tenure, single parent family status, family history of psychiatric disorders and general mental health at age 8 years.

contrasts, however, with previous findings in adolescence (van Os et al. 1997) and adulthood (van Os et al. 1997; Zammit et al. 2004; Koenen et al. 2009) that identified lower cognitive ability as an antecedent of later affective disturbance. Depressive symptomatology in this research, however, was predominantly defined through clinical diagnoses (Zammit et al. 2004; Koenen et al. 2009) or fell within the upper range of a continuous spectrum (van Os et al. 1997), and depression measures during adolescence were based on teacher-report (van Os et al. 1997). Differences between our and other findings may therefore relate to study design and age/pubertal stage at SMFQ assessment, especially as our findings were consistent with other studies using self-reported measures (Hatch et al. 2007).

\section{Strengths and limitations}

Our study has several strengths, including the analysis of continuous change in depressive symptomatology as a function of baseline IQ score across time and the investigation of pubertal stage as well as age. We employed validated instruments to measure IQ score and utilized validated, repeated and self-reported measures of depressive symptoms. All regression estimates were adjusted for a wide range of potential confounding factors related to social adversity, and general mental health at baseline. Sensitivity analysis demonstrated that our findings were unrelated to the presence of non-affective subclinical symptoms during adolescence such as PLIKS. Although there was disproportionate loss to follow-up for SMFQ assessments at 17 years that were sent out as a questionnaire by mail, our results are unlikely to be affected by missing data, as they were unaltered after imputation. A limitation of the study was that SMFQ scores were only available at four different time points during adolescence (11, 13, 14 and 17 years) and it will be of interest to examine the association between IQ score and depressive symptoms as the young people get older. As the observed associations at 13 and 14 years (and in males at 17 years) contrast the cognitive reserve hypothesis, we also need to consider type I error, although this is an unlikely explanation of our data given the observed strength of the association. We were also unable to disentangle the relationship between age and pubertal stage. We provide evidence that the association with IQ changes with both variables but cannot comment on which is more important in this age group.

\section{Explaining the association}

Recent human and animal research has shown that common biological mechanisms can fundamentally differ in childhood, adolescence and adulthood (Romeo \& McEwen, 2006; McCormick \& Mathews, 2007). Indeed, it is known that prepubertal individuals exhibit a significantly prolonged stress reaction compared with adults exposed to the same stressor and that their brain is more sensitive to the stress hormone corticosterone compared with an adult brain (Romeo \& McEwen, 2006; McCormick \& Mathews, 2007). Individuals with a higher cognitive ability, who have better problem-solving skills and coping resources and are more stress-resilient (Smith \& Carlson, 1997), may therefore develop fewer depressive symptoms, especially during early puberty and adolescence when adult stress-management systems are not in place yet (Romeo \& McEwen, 2006; McCormick \& Mathews, 2007). 
Transition into puberty has been associated with an enhanced risk of affective symptoms (Angold et al. 1998). Furthermore, several studies documented that timing of puberty (Schambach et al. 1979; Galatzer et al. 1984; Ehrhardt \& Meyer-Bahlburg, 1994) and age of menarche in girls (Douglas \& Ross, 1964) relate to cognitive ability. Especially, an early entry into puberty has been linked to an increase in mental health problems during mid-adolescence (Kaltiala-Heino et al. 2003). Thus, an IQ-related entry into puberty that is coupled with the onset of affective symptoms may potentially mask the underlying inverse association between early IQ and depressive symptoms. A shift in pubertal stage-specific influences due to an IQ-related entry is, however, an unlikely explanation for the observed risk effect of higher IQ scores in midadolescence, as the effect was confirmed by the analysis in relation to Tanner score. Nevertheless, an IQ-linked entry into puberty may also relate to an increase in affective symptoms through other mechanisms such as those associated with early maturation (e.g. Ge et al. 1996, 2001; Graber et al. 1997; Hayward et al. 1997). Compared with their age-mates, early-maturing girls in particular seem to experience higher levels of stress, especially among heterosexual friends, and have an increased vulnerability towards emotional and behavioural problems, and prior psychological distress (e.g. Ge et al. 1996; Hayward et al. 1997). Some research showed that pubertal timing may also affect males such that early-maturing boys experience more externalized hostile feelings and internalized distress symptoms, compared with on-time or late-maturing age-mates (Ge et al. 2001), although the associated problems are likely to be less severe than in girls (Graber et al. 1997).

It could be speculated that the reappearance of the protective effect of higher childhood IQ in early adulthood, as observed for females at age 17 years, could reflect the end of pubertal development as, for example, biological stress-management systems improve during puberty. This involves the reshaping of the HPA axis to adult functionality, allowing for a more quickly terminated stress response due to the maturation of negative feedback systems, and the pubertal maturation of brain regions which are involved in stress reactivity and emotionality such as the hippocampal formation, the amygdala and the prefrontal cortex (Romeo \& McEwen, 2006; McCormick \& Mathews, 2007). Findings from genetic research (Kendler et al. 2008) further support the idea that there is heterogeneity among risk factors for childhood, adolescent and early adulthood depression. Finally, it could be hypothesized that the absence of a reversal in IQ effect in males at age 17 years, such as that observed for females, may reflect a delay in pubertal development, as males finish some aspects of pubertal development later than females (Archibald et al. 2008).

In conclusion, this study provided evidence that the association between cognitive ability in childhood and depressive symptoms in adolescence varies according to age and/or pubertal stage. This implies differences in the aetiologies underlying depressive symptomatology during adolescence.

\section{Acknowledgements}

We are grateful to all the families who took part in ALSPAC, the midwives for their help in recruiting them, and the whole ALSPAC team, which includes interviewers, computer and laboratory technicians, clerical workers, research scientists, volunteers, managers, receptionists and nurses. The UK Medical Research Council (grant no. 74882), the Wellcome Trust (grant no. 076467/Z05/z) and the University of Bristol provided core support for ALSPAC and this work. This publication is the work of the authors and they will serve as guarantors for the contents of this paper.

\section{Note}

Supplementary material accompanies this paper on the Journal's website (http:/ /journals.cambridge.org/ psm).

\section{Declaration of Interest}

None.

\section{References}

Adebamowo C, Heron J, Butler R, Von Gontard A, Butler U, Emond A, Golding J (2007). A United Kingdom population-based study of intellectual capacities in children with and without soiling, daytime wetting, and bed-wetting. Pediatrics 120, e308-e316.

Angold A, Costello E, Messer C, Pickles A, Winder F, Silver D (1995). The development of a short questionnaire for use in epidemiological studies of depression in children and adolescents. International Journal of Methods in Psychiatric Research 5, 237-249.

Angold A, Costello E, Worthman CM (1998). Puberty and depression: the roles of age, pubertal status and pubertal timing. Psychological Medicine 28, 51-61.

Archibald A, Graber J, Brooks-Gunn J (2008). Pubertal processes and physiological growth in adolescence. In Blackwell Handbook of Adolescence (ed. G. Adams and M. Berzonsky), pp. 24-47. Blackwell Publishing Ltd: Oxford.

Barnett JH, Salmond CH, Jones PB, Sahakian BJ (2006). Cognitive reserve in neuropsychiatry. Psychological Medicine 36, 1053-1064. 
Bates D, Maechler M (2009). Package 'lme4'. http:/ / cran. r-project.org/web/packages/lme4/lme4.pdf (accessed 19 November 2009).

Batty G, Mortensen E, Osler M (2005). Childhood IQ in relation to later psychiatric disorder: evidence from a Danish birth cohort study. British Journal of Psychiatry 187, 180-181.

Biro FM, Lucky AW, Simbartl LA, Barton BA, Daniels SR, Striegel-Moore R, Kronsberg SS, Morrison JA (2003). Pubertal maturation in girls and the relationship to anthropometric changes: pathways through puberty. Journal of Pediatrics 142, 643-646.

Blance A, Tu Y, Gilthorpe MS (2005). A multilevel modelling solution to mathematical coupling. Statistical Methods in Medical Research 14, 553-565.

Caspi A, Moffitt TE (1991). Individual differences are accentuated during periods of social change: the sample case of girls at puberty. Journal of Personality and Social Psychology 61, 157-168.

Cole D, Tram J, Martin J, Hoffman K, Ruiz M, Jacquez F, Maschman T (2002). Individual differences in the emergence of depressive symptoms in children and adolescents: a longitudinal investigation of parent and child reports. Journal of Abnormal Psychology 111, 156-165.

Conger JJ, Galambos NL (1996). Adolescence and Youth. Longman: New York.

Court JH, Raven J (1982). Summaries of reliability, validity, and normative studies for Raven's Progressive Matrices and Vocabulary Scales. In A Manual for Raven's Progressive Matrices and Mill Hill Vocabulary Scales (Research Suppl. No. 2). H. K. Lewis: London.

CRAN (2008). The Comprehensive R Archive Network (http://cran.r-project.org/). Accessed 29 September 2008.

Dale A, Marsh C (1993). The 1991 Census User's Guide. Office for National Statistics: London.

Douglas J, Ross J (1964). Age of puberty related to educational ability, attainment and school leaving age. Journal of Child Psychology and Psychiatry, and Allied Disciplines 47, 185-196.

Ehrhardt AA, Meyer-Bahlburg HF (1994). Psychosocial aspects of precocious puberty. Hormone Research 41 (Suppl. 2), 30-35.

Fry AF, Hale S (2000). Relationships among processing speed, working memory, and fluid intelligence in children. Biological Psychology 54, 1-34.

Galatzer A, Beth-Halachmi N, Kauli R, Laron Z (1984). Intellectual function of girls with precocious puberty. Pediatrics 74, 246-249.

Ge X, Conger RD, Elder GH (2001). The relation between puberty and psychological distress in adolescent boys. Journal of Research on Adolescence 11, 49-70.

Ge X, Rand D, Conger RD, Elder GH (1996). Coming of age too early: pubertal influences on girls' vulnerability to psychological distress. Child Development 67, 3386-3400.

Gelman A, Hill J (2007). Data Analysis using Regression and Multilevel/Hierarchical Models. Cambridge University Press: Cambridge, UK.

Golding J, Pembrey M, Jones R (2001). ALSPAC - the Avon Longitudinal Study of Parents and Children. I. Study methodology. Paediatric and Perinatal Epidemiology 15, 74-87.

Goodman R (1997). The Strengths and Difficulties Questionnaire: a research note. Journal of Child Psychology and Psychiatry 38, 581-586.

Goodman R, Ford T, Richards S, Gatward R, Meltzer H (2000). The Development and Well-Being Assessment: description and initial validation of an integrated assessment of child and adolescent psychopathology. Journal of Child Psychology and Psychiatry, and Allied Disciplines 41, 645-655.

Goodman SH, Brand SR (2009). Depression and early adverse experiences. In Handbook of Depression, 2nd edn (ed. I. H. Gotlib and C. L. Hammen). Guilford Press : New York.

Graber JA, Lewinsohn PM, Seeley JR, Brooks-Gunn J (1997). Is psychopathology associated with the timing of pubertal development? Journal of the American Academy of Child and Adolescent Psychiatry 36, 1768-1776.

Gunnell D, Harrison G, Rasmussen F, Fouskakis D, Tynelius P (2002). Associations between premorbid intellectual performance, early-life exposures and early-onset schizophrenia. Cohort study. British Journal of Psychiatry: The Journal of Mental Science 181, 298-305.

Gunnell D, Magnusson P, Rasmussen F (2005). Low intelligence test scores in 18 year old men and risk of suicide: cohort study. British Medical Journal (Clinical Research Ed.) 330, 167.

Hatch S, Jones P, Kuh D, Hardy R, Wadsworth M, Richards M (2007). Childhood cognitive ability and adult mental health in the British 1946 birth cohort. Social Science and Medicine (1982) 64, 2285-2296.

Hayward C, Killen JD, Wilson DM, Hammer LD, Litt IF, Kraemer HC, Haydel F, Varady A, Taylor CB (1997). Psychiatric risk associated with early puberty in adolescent girls. Journal of the American Academy of Child and Adolescent Psychiatry 36, 255-262.

Horwood J, Salvi G, Thomas K, Duffy L, Gunnell D, Hollis C, Lewis G, Menezes P, Thompson A, Wolke D, Zammit S, Harrison G (2008). IQ and non-clinical psychotic symptoms in 12-year-olds: results from the ALSPAC birth cohort. British Journal of Psychiatry 193 185-191.

Kaltiala-Heino R, Marttunen M, Rantanen P, Rimpelä M (2003). Early puberty is associated with mental health problems in middle adolescence. Social Science and Medicine 57, 1055-1064.

Keating D (2004). Cognitive and brain development. In Handbook of Adolescent Psychology (ed. R. Lerner and L. Steinberg), pp. 45-84. Wiley: New Jersey.

Kendler K, Gardner C, Lichtenstein P (2008). A developmental twin study of symptoms of anxiety and depression: evidence for genetic innovation and attenuation. Psychological Medicine 38, 1567-1575.

Koenen KC, Moffitt TE, Roberts AL, Martin L, Kubzansky L, Harrington H, Poulton R, Caspi A (2009). Childhood IQ and adult mental disorders: a test of the cognitive reserve hypothesis. American Journal of Psychiatry 166, 50-57. 
Lupien SJ, McEwen BS, Gunnar MR, Heim C (2009). Effects of stress throughout the lifespan on the brain, behaviour and cognition. Nature Reviews. Neuroscience 10, 434-445.

McCormick C, Mathews I (2007). HPA function in adolescence: role of sex hormones in its regulation and the enduring consequences of exposure to stressors.

Pharmacology, Biochemistry, and Behavior 86, 220-233.

McEwen BS (2005). Glucocorticoids, depression, and mood disorders: structural remodeling in the brain. Metabolism 54 (Suppl. 1), 20-23.

Mortensen E, Sørensen H, Jensen H, Reinisch J, Mednick S (2005). IQ and mental disorder in young men. British Journal of Psychiatry: The Journal of Mental Science 187, 407-415.

Oudshoorn CGM, van Buuren S, van Rijckevorsel JLA (1999). Flexible Multiple Imputation by Chained Equations of the AVO-95 Survey. TNO Prevention and Health: Leiden.

Peterson AC, Taylor B (1980). The biological approach to adolescence. In Handbook of Adolescent Psychology (ed. J. Adelson), pp. 117-155. Wiley: New York.

Romeo R, McEwen BS (2006). Stress and the adolescent brain. Annals of the New York Academy of Sciences 1094, 202-214.

Rudolph KD, Hammen C (1999). Age and gender as determinants of stress exposure, generation, and reactions in youngsters: a transactional perspective. Child Development 70, 660-677.

Sapolsky RM, Krey LC, McEwen BS (1986). The neuroendocrinology of stress and aging: the glucocorticoid cascade hypothesis. Endocrine Reviews 7, 284-301.

Scarmeas N, Stern Y (2003). Cognitive reserve and lifestyle. Journal of Clinical and Experimental Neuropsychology 25, 625-633.
Schambach H, Schneemann K, Müller E (1979). Psychic and intellectual development in girls with precocious puberty. Endokrinologie 74, 47-51.

Smith C, Carlson BE (1997). Stress, coping, and resilience in children and youth. Social Service Review 71, 231-256.

Steinberg L (2005). Cognitive and affective development in adolescence. Trends in Cognitive Sciences 9, 69-74.

Tanner J (1962). Growth at Adolescence, 2nd edn. Blackwell Scientific: Oxford.

Thapar A, McGuffin P (1998). Validity of the shortened Mood and Feelings Questionnaire in a community sample of children and adolescents : a preliminary research note. Psychiatry Research 81, 259-268.

van Os J, Jones P, Lewis G, Wadsworth M, Murray R (1997). Developmental precursors of affective illness in a general population birth cohort. Archives of General Psychiatry 54, 625-631.

Wechsler D, Golombok J, Rust J (1992). WISC-III UK Wechsler Intelligence Scale for Children - UK Manual, 3rd edn. The Psychological Corporation: Sidcup, UK.

Whalley LJ, Deary IJ (2001). Longitudinal cohort study of childhood IQ and survival up to age 76. British Medical Journal 322, 819.

Woodberry KA, Giuliano AJ, Seidman LJ (2008). Premorbid IQ in schizophrenia: a meta-analytic review. American Journal of Psychiatry 165, 579-587.

Zammit S, Allebeck P, David A, Dalman C, Adam T, Lundberg I, Lewis G (2004). A longitudinal study of premorbid IQ score and risk of developing schizophrenia, bipolar disorder, severe depression, and other nonaffective psychoses. Archives of General Psychiatry 61, 354-360. 